\title{
Segmental uncoverage ratio analysis of Crowe type-IV developmental dysplasia of the hip via 3-dimensional implantation simulation
}

Yiming Dou ${ }^{\dagger}$, Jianlin Xiao ${ }^{\dagger}$, Xinggui Wen, Jianpeng Gao, Hao Tian and Jianlin Zuo*

\begin{abstract}
Background: To study the segmental uncoverage ratio (UCR) of a 44-mm cup model placed in a true acetabulum of Crowe type-IV developmental dysplasia of the hip via 3-Dimensional (3D) implantation simulation.

Methods: Qualified CT imaging data of 26 patients (involving 30 hips) with Crowe type-IV DDH were imported into Mimics software for reconstruction. Then a 44-mm eggshell cup model was placed in a true acetabulum. First, total uncoverage ratio (TUCR) was measured. Then the virtual cup was divided into 4 segments according to the quadrant setting of the true acetabulum, i.e., anterior-superior (A-S) segment, anterior-inferior (A-I) segment, posterior-superior (P-S) segment and posterior-inferior (P-I) segment. The UCRs of the aforementioned segments were measured, i.e., anterior-superior uncoverage ratio (A-SUCR), anterior-inferior uncoverage ratio (A-IUCR), posterior-superior uncoverage ratio (P-SUCR) and posterior-inferior uncoverage ratio (P-IUCR). The acetabular height and anterior-posterior diameter on the 3-D model were also calculated. Statistic analyses were performed by using SPSS software package.

Results: TUCR was $0.2958 \pm 0.1003$ (95\% [Cl], 0.1020 to 0.5400) in this cohort of Crowe Type-IV hips. P-SUCR had the greatest value among all the segmental UCRs $(0.1012 \pm 0.0435,95 \%$ confidence interval $[\mathrm{Cl}], 0.0152$ to 0.1914$)$ and the most significant positive correlation with TUCR (Pearson correlation $=0.889, p<0.01$. Linear regression $\mathrm{R}^{2}=$ 0.791). Similarly, P-IUCR and A-SUCR showed a significant positive correlation with TUCR. However, A-IUCR exhibited no correlation with either total or other segmental UCRs. P-SUCR was found to bear significant positive correlation with $\mathrm{P}-\mathrm{IUCR}$ (pearson correlation $=0.644, p<0.01$. Linear regression $\mathrm{R}^{2}=0.415$ ). Acetabular height and A-P diameter were not correlated with TUCR.

Conclusion: Implantation of a 44-mm cup into Crowe type IV acetabulum is feasible and could achieve acceptable host bone coverage in most of the cases. P-SUCR contributed most to TUCR. TUCR had no linear relationship with the size of the host acetabulum, suggesting that the pre-operative plan should be individualized.
\end{abstract}

Keywords: Developmental dysplasia of hip, Total hip arthroplasty, Segmental uncoverage ratio, 3-D implantation simulation

\footnotetext{
* Correspondence: jianlinzuo@sina.com

†Yiming Dou and Jianlin Xiao contributed equally to this work.

Department of Orthopaedics, China-Japan Union Hospital of Jilin University,

No. 126, Xiantai Street, Changchun 130033, Jilin Province, China
}

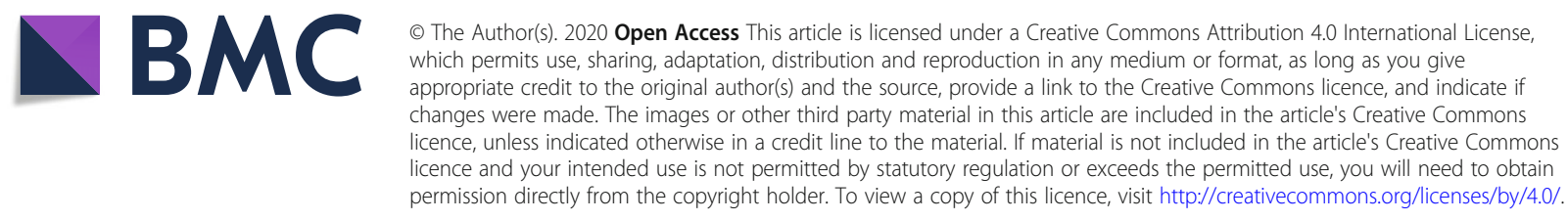




\section{Introduction}

Developmental dysplasia of the hip (DDH) represents the most common cause leading to secondary osteoarthritis of hip. As the disease progresses, patients may develop such symptoms as hip pain, limitation of movement, which can seriously affect the quality of life of the patients [1-3]. For severe DDH, total hip arthroplasty (THA) is an effective treatment which can relieve pain and help the join regain function. DDH is morphologically classified in different ways, including the Crowe classification and the Hartofilakidis method [4, 5]. Due to the complexity of acetabular anatomy, the treatment of the acetabulum varies widely. Different operative principles apply with different classifications, and even within one classification, surgery strategies vary. Among those classifications, Crowe type-IV acetabula are often small and shallow, irregular in shape, and may be associated with bone defects. Mulroy and Harris et al mentioned that, in order to prevent mechanical graft failure, a $70 \%$ coverage of the cup by host bone is recommended [6]. With Crowe type-IV DDH, it is an feasible choice to use a 44-mm cup to achieve a balance between small bone volume in a true acetabulum and adequate cup size for hip stability. So far, few three-dimensional studies focused on the uncoverage ratio of this type of $\mathrm{DDH}$. Our research questions are as follows: What are the segmental uncoverage ratios of a 44- $\mathrm{mm}$ cup placed in a true acetabulum in Crowe type-IV DDH and what are their influencing factors? We aimed to address these questions via three-dimensional implantation simulation.

\section{Materials and methods}

\section{Study subjects}

We retrospectively reviewed the preoperative imaging data of 115 patients with DDH who were admitted to our institution from January 2010 to August 2018. The patients were categorized according to the Crowe classification. Of them, 30 subjects ( 35 hips) were classified as Crowe type-IV. In 2 of the 30 patients, the imaging results were not satisfactory, and 2 had abnormal pelvic morphology. These 4 patients (5 hips) were excluded. Eventually, 26 Crowe type-IV patients (30 hips) were included in our study. Demographic data of the subjects are shown in Table 1.

\section{CT scan and 3-D reconstruction}

Pelvic CT was performed with a Toshiba Aquilion CT scanner $(120 \mathrm{kV}, 320 \mathrm{~mA}, 512 \times 512$ matrix, and $0.5-\mathrm{mm}$ slice thickness). The patients were placed in a supine position with the patellae facing the ceiling. Scan was performed from the iliac crest to the distal one-third of the femur. All CT slices were saved in Digital Imaging and Communications in Medicine (DICOM) format and imported into Mimics software (Version 19.0, Materialise) for 3-D reconstruction. Before measurement, we used the same method to set our standard planes as previously reported [7]. Bilateral anterior-superior iliac spines (ASIS) and pubic tubercles were identified and the coronal plane was established. The sagittal plane was perpendicular to the coronal plane while passing through the mid-point of pubic tubercles, and the horizontal plane was perpendicular to the coronal plane and the sagittal plane. Thus the standard planes were set for the following measurements. Those standard planes are showed in Fig. 1.

\section{3-D implantation simulation of cup model}

We created 2 hemispherical virtual acetabular cup models by means of a 3-matic software package (Version 9.0, Materialise). One was a virtual cup model with an outer diameter of 44- $\mathrm{mm}$ and a shell thickness of $4 \mathrm{~mm}$. Then we performed cup implantation by using the virtual cup model. The other was also a virtual cup component with the same outer diameter but its shell thickness was only $0.01 \mathrm{~mm}$. The model served as an eggshell cup for measuring the uncoverage area. These 3-D models were imported into the Mimics software (Version 19.0, Materialise) in STL (stereolithography) format. In THA patients without hip dysplasia, the cup was selected according to the actual size of the acetabulum. While in THA patients with Crowe type IV hip dysplasia, the bone volume in a true acetabulum was too limited to accommodate a larger cup. In most inventories of the hip prostheses, a 44-mm diameter cup is the smallest one to accommodate a $28-\mathrm{mm}$ head to ensure better range of motion and to lower risk of impingement and dislocation. The diameter of most of the true acetabulum in this type of hip is less than $40 \mathrm{~mm}$. Thus, it is an feasible choice to use a 44-mm cup to accomplish a balance between a small bone volume in true acetabulum and adequate cup size for hip stability.

The following were the rules of our virtual cup replacement. All cup models were implanted into a true acetabulum at an abduction angle of $45^{\circ} \pm 1^{\circ}$ and an anteversion angle of $20^{\circ} \pm 1^{\circ}$. We medialized the cup to make it abut the medial wall to maximize the coverage

Table 1 Demographic data

\begin{tabular}{llllll}
\hline & Hip & Male/Female & Age $^{a}(\mathrm{yr})$ & Height $^{\mathrm{a}}(\mathrm{cm})$ & $\mathrm{BMl}^{\mathrm{a}}\left(\mathrm{kg} / \mathrm{m}^{2}\right)$ \\
\hline Crowe IV & 30 & $2: 24$ & $41.85 \pm 13.14$ & $156.75 \pm 11.03$ & $57.38 \pm 13.08$ \\
DDH & & $(22$ to 70) & (141 to 175) & (33 to 84)
\end{tabular}

${ }^{\mathrm{a}}$ The values are expressed as the mean and the standard deviation, with the $95 \%$ confidence interval in parentheses. $B M I$ Body mass index 


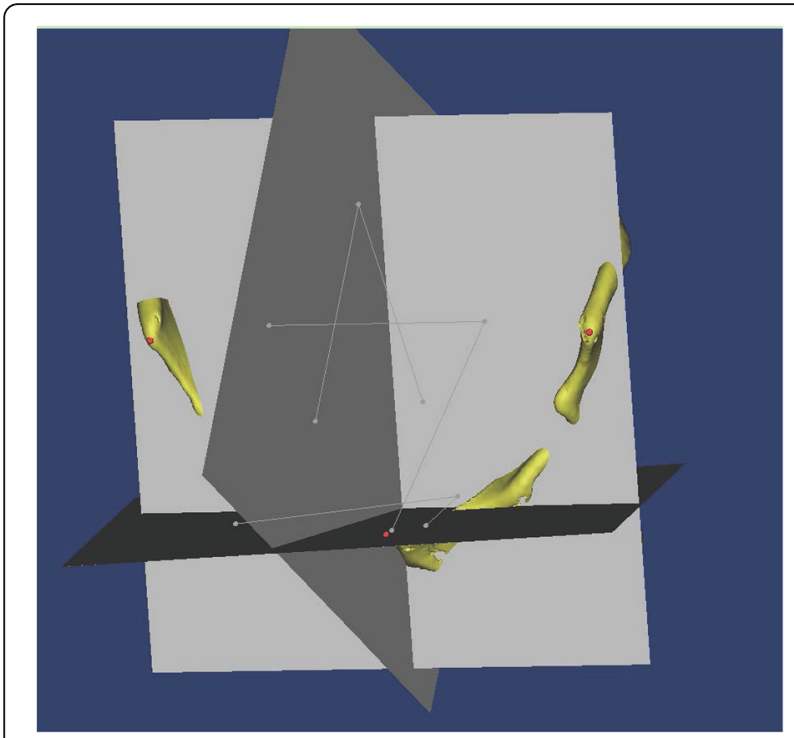

Fig. 1 The coronal plane, sagittal plane and horizontal plane of the pelvis

by host bone. The front edge of cup was tangent to the anterior wall of the true acetabulum, and the lower edge of the cup was tangent to the transverse ligament. Due to the bigger size of the cup, as compared to the size of the true acetabulum, the rotational center would slightly migrate posterior-superiorly. All 44-mm standard cups could be successfully implanted into the true acetabulum with this method. Then we replaced the standard cup model with the eggshell cup model and the uncoverage area was calculated according to the uncovered area of eggshell cup.

\section{3-D acetabular quadrants set and measurements of segmental UCRs}

Wasielewski RC et al divided acetabulum into 4 quadrants in order to find the safe zones for screw fixation [8]. In 2-dimensional image, we drew a line passing through the ipsilateral ASIS and the center of cup as yaxis, and the line passing the center of cup while perpendicular to $y$-axis served as $\mathrm{x}$-axis. In our study, we designated the plane passing through bilateral ASIS and the center of the implanted virtual cup the acetabular quadrantal sagittal plane, and the plane perpendicular to acetabular quadrantal sagittal plane, going through the cup center, was designated acetabular quadrantal horizontal plane. These 2 planes divided the cup into 4 segments: anterior-superior (A-S), anterior-inferior (A$\mathrm{I})$, posterior-superior ( $\mathrm{P}-\mathrm{S})$, posterior-inferior (P-I) segments (Fig. 2). We calculated the uncoverage area of each segment by using the Mimics software (version 19.0, Materialise), and the uncoverage ratio equaled uncoverage area divided by total surface area. (Fig. 3).

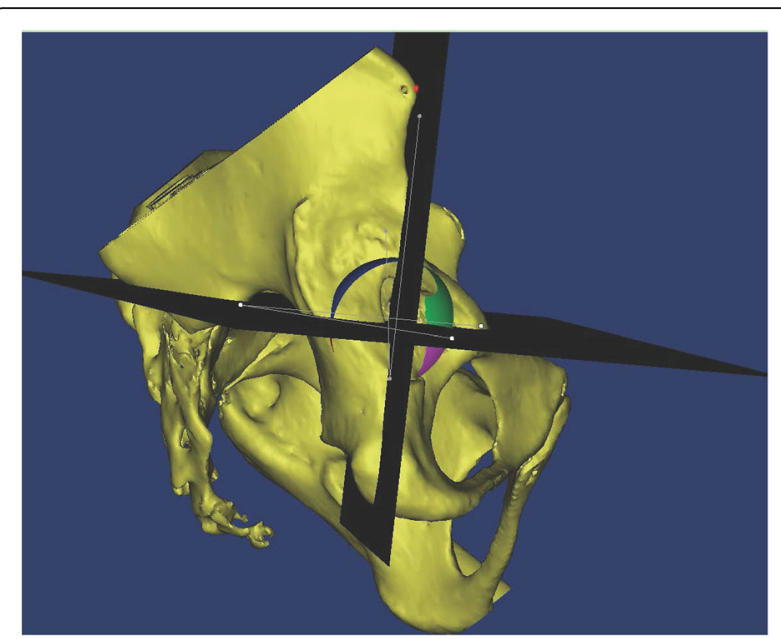

Fig. 2 The acetabular quadrants divided the cup into 4 segments: anterior-superior (AS), anterior-inferior (AI), posterior-superior (PS), posterior-inferior $(\mathrm{PI})$

\section{Measurements of acetabular height and anterior- posterior diameter}

We used Mimics software (Version 19.0, Materialise) to get the coordinates of the most superior point of the true acetabulum and establish the horizontal plane at the level of acetabular lower edge. We applied Matlab software (Version 2016, Mathworks) to calculate the perpendicular distance from the most superior point to the horizontal plane with the following formula: $\mathrm{D}=$ $\operatorname{abs}\left(a^{*} p \quad[1]+b^{*} p \quad[2]+c^{*} p \quad[3]+d\right) / \operatorname{sqrt}\left(a^{\wedge} 2+b^{\wedge} 2+c^{\wedge} 2\right)$.

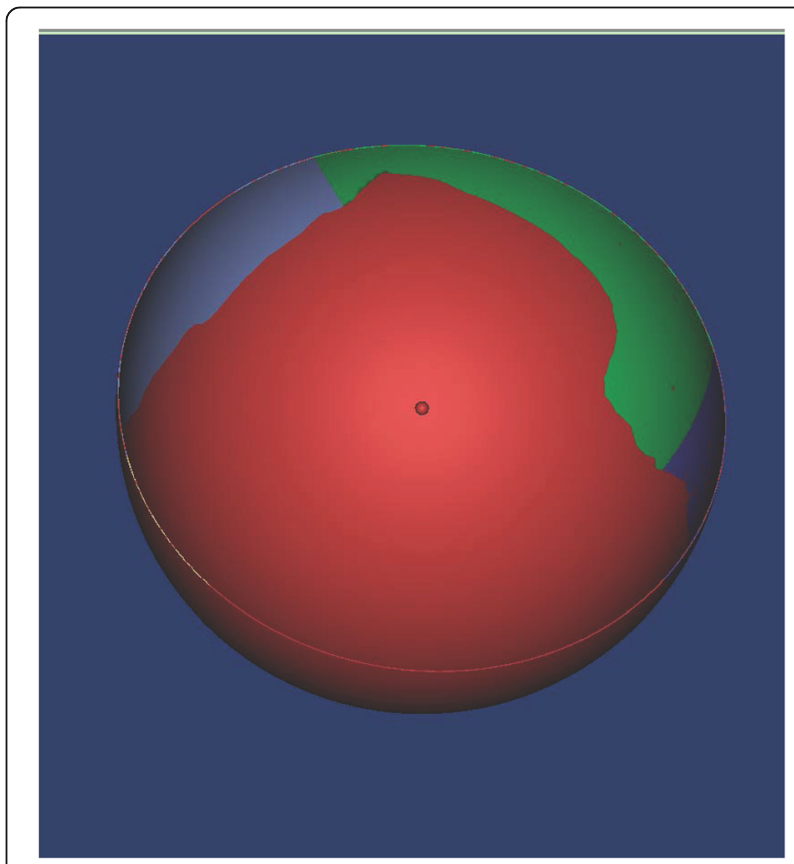

Fig. 3 The uncoverage area of each segments, generated by Mimics software 
Then we placed horizontal plane at the level of $1 / 2$ acetabular height, and the distance from the anterior wall to the posterior wall was A-P diameter of the true acetabulum. In this cohort, the true acetabula was of conic shape, and the standard volumetric formula was $\mathrm{V}=1$ / $3^{*} \pi^{*}{ }^{2 *} \mathrm{H}$. We assumed that there might be a proportional relation between $\mathrm{r}$ and A-P diameter, so we calculated the volume of the true acetabulum with the following formula: $V=H^{*} R^{*} R$ (where $H$ is acetabular height; $\mathrm{R}$ is A-P diameter).

\section{Statistical analysis}

All statistical analyses were performed by the same author using a statistical software package (SPSS Version 20, SPSS Inc., Chicago, IL, USA). The KolmogorovSmirnov test was conducted to find out the distribution pattern of all data. The Pearson test and linear regression analysis were performed to estimate the correlations among UCRs; height, A-P diameter and volume of the acetabulum. The scatter diagrams were plotted to illustrate the correlation pattern of the former data. All data were expressed as mean and standard deviation (SD). All reported $P$-values were 2 -tailed and the significance level was set at 0.05 .

\section{Results}

The results of UCRs were as follows: $0.0832 \pm 0.0427$ (95\% [CI], 0.0303 to 0.1667$)$ for A-SUCR, $0.0521 \pm$ $0.0246(95 \%[\mathrm{CI}], 0.0013$ to 0.1255$)$ for A-IUCR, $0.1012 \pm 0.0435(95 \%[\mathrm{CI}], 0.0152$ to 0.1914$)$ for $\mathrm{P}$ SUCR, $0.0592 \pm 0.0478(95 \%$ [CI], 0 to 0.1568$)$ for PIUCR, and $0.2958 \pm 0.1003 \quad(95 \% \quad[\mathrm{CI}], 0.1020$ to
0.5400) for TUCR. The mean acetabular height was $31.99 \pm 4.09 \mathrm{~mm}(95 \%[\mathrm{CI}], 24.44$ to $40.55 \mathrm{~mm})$. The mean A-P diameter was $25.23 \pm 4.82 \mathrm{~mm} \quad(95 \%[\mathrm{CI}]$, 14.65 to $40.00 \mathrm{~mm})$. The mean volume was 21 , $257.59 \pm 9165.69\left(95 \%[\mathrm{CI}], 5785.17\right.$ to $\left.54,070.88 \mathrm{~mm}^{3}\right)$. Data are detailed in Table 2.

\section{The relationship between acetabular size and UCRs}

Pearson correlation and linear regression analysis showed that the acetabular height bore a significant negative correlation with P-IUCR (Pearson correlation $=-0.585, p<0.01$. Linear regression $R^{2}=0.342$ ) and a significant positive correlation with A-SUCR (Pearson correlation coefficient $=0.395, \quad p<0.05$. Linear regression $\mathrm{R}^{2}=0.156$ ). The acetabular height exhibited no correlation with other UCRs. The A-P diameter displayed no correlation with all UCRs. The acetabular volume had a significant negative correction with P-IUCR (Pearson correlation coefficient $=-0.473, p<0.01$. Linear regression $R^{2}=0.224$ ), but was not correlated with other UCRs. The mean TUCR was $0.2958 \pm 0.1003 \quad(95 \%[C I], \quad 0.1020$ to 0.5400 ). Twenty TUCRs $\leq 0.3$ (mean acetabular height: $32.86 \pm 4.18 \mathrm{~mm}$, from 26.38 to $40.55 \mathrm{~mm}$. mean A-P diameter: $25.00 \pm 4.13 \mathrm{~mm}$, from 14.65 to $31.55 \mathrm{~mm}$ ), while the other 10 TUCRs $>0.3$ (mean acetabular height: $30.67 \pm 3.75 \mathrm{~mm}$, from 24.44 to $35.97 \mathrm{~mm}$. mean A-P diameter: $25.58 \pm 5.89 \mathrm{~mm}$, from 17.53 to 40.00), of which 4 TUCRs $>0.4$. If we designated those TUCRs $>0.3$ group $A$, and TUCRs $\leq 0.3$ group $B$, there were no significant differences in height and A-P

TABLE 2 Statistical results

\begin{tabular}{|c|c|c|c|c|c|c|c|c|c|}
\hline & \multirow[t]{2}{*}{ Measurement } & \multicolumn{8}{|c|}{ Pearson correlation \& Linear regression results } \\
\hline & & ASUCR & AIUCR & PSUCR & PIUCR & TUCR & $\mathrm{H}$ & $\mathrm{R}$ & V \\
\hline$\overline{A S U C R^{*}}$ & $\begin{array}{l}0.0832 \pm 0.0427 \\
(0.0303 \text { to } 0.1667)\end{array}$ & - & - & - & - & $\begin{array}{l}0.461^{a} \\
R^{2}=0.213\end{array}$ & - & - & - \\
\hline AIUCR* & $\begin{array}{l}0.0521 \pm 0.0246 \\
(0.0013 \text { to } 0.1255)\end{array}$ & - & - & - & - & - & - & - & - \\
\hline PSUCR* & $\begin{array}{l}0.1012 \pm 0.0435 \\
(0.0152 \text { to } 0.1914)\end{array}$ & - & - & - & $\begin{array}{l}0.644^{b} \\
R^{2}=0.415\end{array}$ & $\begin{array}{l}0.889^{b} \\
R^{2}=0.791\end{array}$ & - & - & - \\
\hline PIUCR* & $\begin{array}{l}0.0592 \pm 0.0478 \\
(0 \text { to } 0.1568)\end{array}$ & - & - & - & - & $\begin{array}{l}0.768^{b} \\
R^{2}=0.590\end{array}$ & - & - & - \\
\hline TUCR* & $\begin{array}{l}0.2958 \pm 0.1003 \\
(0.1020 \text { to } 0.5400)\end{array}$ & - & - & - & - & - & - & - & - \\
\hline $\mathrm{H}^{*}$ & $\begin{array}{l}31.99 \pm 4.09 \\
(24.44 \text { to } 40.55)\end{array}$ & $\begin{array}{l}0.395^{a} \\
R^{2}=0.156\end{array}$ & - & - & $\begin{array}{l}-0.585^{b} \\
R^{2}=0.342\end{array}$ & - & - & - & - \\
\hline$R^{*}$ & $\begin{array}{l}25.23 \pm 4.82 \\
(14.65 \text { to } 40.00)\end{array}$ & - & - & - & - & - & - & - & - \\
\hline$V^{*}$ & $\begin{array}{l}21,257.59 \pm 9165.69 \\
(5785.17 \text { to } 54,070.88)\end{array}$ & - & - & - & $\begin{array}{l}-0.473^{b} \\
R^{2}=0.224\end{array}$ & - & - & - & - \\
\hline
\end{tabular}

AS Anterior-superior, Al Anterior-inferior, PS Posterior-superior, PI Posterior-inferior, UCR Uncoverage ratio, $H$ Acetabular height, $R$ Anterior-posterior diameter, $V$ V $=$ $\mathrm{H}^{*} \mathrm{R} * \mathrm{R}, \mathrm{V}$ as acetabular volume ${ }^{\mathrm{a}} p<0.05$. ${ }^{\mathrm{b}} p<0.01$ 
diameter of the true acetabulum between the two groups.

\section{The relationship between each segmental UCR and TUCR} P-SUCR showed a significant positive correlation with P-IUCR (Pearson correlation coefficient $=0.644, p<0.01$. Linear regression $\left.\mathrm{R}^{2}=0.415\right)$. P-SUCR exhibited a significant positive correlation with TUCR (Pearson correlation coefficient $=0.889, p<0.01$. Linear regression $\mathrm{R}^{2}=$ 0.791), so did P-IUCR and A-SUCR (Pearson correlation coefficient $=0.768, p<0.01$. Linear regression $\mathrm{R}^{2}=0.590$ for P-IUCR and Pearson correlation coefficient $=0.461$, $p<0.01$. Linear regression $\mathrm{R}^{2}=0.213$ for A-SUCR). AIUCR showed no correlation with TUCR.

\section{Discussion}

This study showed that the mean TUCR was $0.2958 \pm 0.1003(95 \%[\mathrm{CI}], 0.1020$ to 0.5400$)$, which means implanting a 44-mm cup into a true acetabulum is workable in most Crowe type-IV DDH hips. Nonetheless, with some hips, TUCRs are more than 0.3 and some surgical techniques should be used with these hips to secure adequate coverage ratio, such as structural bone grafts, high placement of cup, extrasmall cup, posterior-superior placement of cup, medial protrusio technique, among others [9-11] These techniques, however, may negatively impact the longterm survival of the implants. Previous studies revealed that the long-term failure rate of structural bone grafts was high $(39-75 \%)[6,11,12]$, and using extra-small cup would decrease femoral head-neck radio and thereby increase shear stress. High placement of cup may compromise the biomechanical property and then shorten the long-term survival of the hip [13]. This study demonstrated that no significant difference was found in the height, A-P diameter and volume of the true acetabulum between the TUCR 0.3 minus group and the TUCR 0.3 plus group. This finding has two implications. First, surgeons must make individualized plans for each single $\mathrm{DDH}$ patient, because larger true acetabulum does not mean better coverage. Second, host bone stock in the true acetabulum is not quantitatively related to the size of the true acetabulum. Hence, a 44-mm cup is not contraindicated for a small true acetabulum.

As for the placement location of cup, Hartofilakidis et al proposed that surgeons should ream towards posterior-superior direction, because bone stock in that direction is usually adequate [14]. Sen C et al and Greber EM et al indicated that the bone stock of the posterior column is sufficient while the bone stock of the anterior-superior wall is insufficient [15, 16]. Dorr et al proposed a medial protrusio technique which could maximize host bone coverage to the cup
[17]. Dunn et al mentioned a medial wall breakthrough technique which could further maximize host bone coverage to the cup [9]. In our study we found that 10 TUCRs $>0.3$, of which 4 TUCRs $>0.4$. Thus it is reasonable to use one of the previous techniques to enhance coverage of host bone to the cup when the uncoverage ratio is unacceptable.

Few studies so far analyzed the segmental uncoverage ratio of the cup of Crowe type IV DDH. We believe that each segment contributes, to various degrees, to the total coverage. Out study showed that the mean P-SUCR was $0.1012 \pm 0.0435$ and bore the most significant positive correlation with TUCR, suggesting that P-SUCR affects TUCR most. Given that P-SUCR is very important during cup insertion, when P-SUCR is seriously inadequate we should consider structural bone grafting or other coverage-enhancing techniques.

This study had some limitations. First, there were too few male subjects ( 2 males, while 24 females). As a result, conclusion should be applied to male Crowe typeIV patients with discretion. Second, the number of subjects in this cohort was relatively small, this might affect the significance of differences in some parameters, such as the uncoverage ratio and true acetabulum size. Third, we set the anterior pelvic plane as the standard plane without involving the pelvic tilt angle and this omission might influence the functional acetabular anteversion during operation. Fourth, the 44-mm cup was chosen for all patients in this study. Some Crowe type IV hips may accommodate 44-mm+ cups, although the diameter of most of the true acetabula in this type of hip is less than $40 \mathrm{~mm}$.

\section{Conclusion}

Our study showed that implantation of a 44-mm cup in Crowe type IV acetabulum was feasible and could achieve acceptable host bone coverage in the majority of cases. For those patients with an unacceptable uncoverage ratio, it is reasonable to perform structural bone grafting or other coverage-enhancing techniques. PSUCR contributed most to TUCR. TUCR bore no linear relationship with the size of the host acetabulum, suggesting that the preoperative plan should be individualized.

\section{Abbreviations}

DDH: Developmental dysplasia of the hip; UCR: Uncoverage ratio; TUCR: Total uncoverage ratio; A-SUCR: Anterior-superior uncoverage ratio; AIUCR: Anterior-inferior uncoverage ratio; P-SUCR: Posterior-superior uncoverage ratio; P-IUCR: Posterior-inferior uncoverage ratio; STL: Stereolithography

Acknowledgements

No. 


\section{Authors' contributions}

Yiming Dou: Analysis and interpretation of data, drafting of the manuscript. Jianlin Xiao: Design of the work and interpretation of data. Xinggui Wen: Acquisition and analysis of data. Jianpeng Gao: Acquisition of data. Hao Tian: Acquisition of data. Jianlin Zuo: Design of the work and substantial involvement in the revision of the manuscript. Corresponding author. Yiming Dou and Jianlin Xiao contributed equally to this project. The authors read and approved the final manuscript.

\section{Funding}

No funding was involved in this study.

\section{Availability of data and materials}

The datasets used and/or analysed during the current study are available from the corresponding author on reasonable request.

\section{Ethics approval and consent to participate}

This study was approved by the ethics committee of our institution, and informed consent was obtained from all the patients.

\section{Consent for publication}

Not applicable.

\section{Competing interests}

The authors declare that they have no competing interests.

Received: 10 January 2020 Accepted: 16 April 2020

Published online: 19 May 2020

\section{References}

1. Rosenstein AD, Diaz RJ. Challenges and solutions for total hip arthroplasty in treatment of patients with symptomatic sequelae of developmental dysplasia of the hip. Am J Orthop (Belle Mead NJ). 2011:40(2):87-91.

2. Krych AJ, Howard JL, Trousdale RT, Cabanela ME, Berry DJ. Total hip arthroplasty with shortening subtrochanteric osteotomy in Crowe type-IV developmental dysplasia. J Bone Joint Surg. 2009;91(9):2213-21.

3. Harris WH. Etiology of osteoarthritis of the hip. Clin Orthop Relat Res. 1986; 213:20-33.

4. Crowe JF, Mani VJ, Ranawat CS. Total hip replacement in congenital dislocation and dysplasia of the hip. J Bone Joint Surg. 1979;61(1):15-23.

5. Hartofilakidis G, Stamos K, loannidis TT. Low friction arthroplasty for old untreated congenital dislocation of the hip. J Bone Joint Surg. 1988;70(2): 182-6.

6. Mulroy RD Jr, Harris WH. Failure of acetabular autogenous grafts in total hip arthroplasty. Increasing incidence: a follow-up note. J Bone Joint Surg. 1990; 72(10):1536-40.

7. Yang Y, Zuo J, Liu T, Xiao J, Liu S, Gao Z. Morphological analysis of true acetabulum in hip dysplasia (Crowe classes I-IV) via 3-D implantation simulation. J Bone Joint Surg. 2017;99(17):e92.

8. Wasielewski RC, Cooperstein LA, Kruger MP, Rubash HE. Acetabular anatomy and the transacetabular fixation of screws in total hip arthroplasty. J Bone Joint Surg. 1990;72(4):501-8.

9. Dunn HK, Hess WE. Total hip reconstruction in chronically dislocated hips. J Bone Joint Surg. 1976;58(6):838-45.

10. Komiyama K, Nakashima Y, Hirata M, Hara D, Kohno Y, Iwamoto Y. Does high hip center decrease range of motion in Total hip arthroplasty? A computer simulation study. J Arthroplasty. 2016:31(10):2342-7.

11. Delimar D, Aljinovic A, Bicanic G. Failure of bulk bone grafts after total hip arthroplasty for hip dysplasia. Arch Orthop Trauma Surg. 2014; 134(8):1167-73.

12. Lee BP, Cabanela ME, Wallrichs SL, Ilstrup DM. Bone-graft augmentation for acetabular deficiencies in total hip arthroplasty. Results of long-term followup evaluation. J Arthroplasty. 1997;12(5):503-10.

13. Rogers BA, Garbedian S, Kuchinad RA, Backstein D, Safir O, Gross AE Total hip arthroplasty for adult hip dysplasia. J Bone Joint Surg. 2012; 94(19):1809-21.

14. Hartofilakidis G, Stamos K, Karachalios T. Treatment of high dislocation of the hip in adults with total hip arthroplasty. Operative technique and longterm clinical results. J Bone Joint Surg. 1998:80(4):510-7.
15. Sen C, Bilsel K, Elmadag M, Gunes T, Saygi B. Acetabuloplasty at the anatomic Centre for treating Crowe class III and IV developmental hip dysplasia: a case series. Hip Int. 2016;26(4):360-6.

16. Greber EM, Pelt CE, Gililland JM, Anderson MB, Erickson JA, Peters CL. Challenges in Total hip arthroplasty in the setting of developmental dysplasia of the hip. J Arthroplasty. 2017;32(9s):S38-s44.

17. Dorr LD, Tawakkol S, Moorthy M, Long W, Wan Z. Medial protrusio technique for placement of a porous-coated, hemispherical acetabular component without cement in a total hip arthroplasty in patients who have acetabular dysplasia. J Bone Joint Surg. 1999;81(1):83-92.

\section{Publisher's Note}

Springer Nature remains neutral with regard to jurisdictional claims in published maps and institutional affiliations.
Ready to submit your research? Choose BMC and benefit from:

- fast, convenient online submission

- thorough peer review by experienced researchers in your field

- rapid publication on acceptance

- support for research data, including large and complex data types

- gold Open Access which fosters wider collaboration and increased citations

- maximum visibility for your research: over $100 \mathrm{M}$ website views per year

At BMC, research is always in progress.

Learn more biomedcentral.com/submissions 